\title{
AFRONTAMIENTO RELIGIOSO ESPIRITUAL DE LA PÉRDIDA DE UN SER QUERIDO
}

\section{Religious and spiritual coping of the loss of a loved one}

Laura Yoffe*

\section{Resumen}

Este artículo analiza la modalidad de afrontamiento religioso espiritual de un suceso negativo y estresante como la pérdida por muerte de un ser querido. Incluye el estudio de caso de una mujer religiosa de credo católico participante de mi investigación de Tesis Doctoral (realizada como estudio exploratorio descriptivo con sujetos religiosos de distintos credos) en el cual se constató que las plegarias, la meditación, la sanación espiritual, los rituales funerarios y el apoyo social colaboran en la promoción de estados positivos de bienestar psicofísico, mental y espiritual de deudos religiosos.

Palabras clave: Afrontamiento, duelo, religión, espiritualidad, bienestar.

\begin{abstract}
This article analyses religious and spiritual coping of negative and stressful events such as the loss of a loved one. The study case of a religious catholic woman who lost a loved one is part of my Docthoral Thesis (an exploratory and descriptive study done with religious persons of different creeds), where it was verified that prayers, meditation, spiritual healing, funerary rituals and social support promote positive effects and physical, psychological, mental and spiritual well- being of religious people who mourn the loss of a loved one.
\end{abstract}

Keywords: Coping, bereavement, religion, spirituality, well-being.

\footnotetext{
* Psicóloga. Psicoterapeuta corporal en biosíntesis. laurayoffe@ hotmail.com
} 


\section{AFRONTAMIENTO DE LA PÉRDIDA DE UN SER QUERIDO}

La pérdida de un "ser querido" - padre/ madre, hermano/ hermana, marido o esposa o hijo/a- se encuentra entre los sucesos vitales negativos, estresantes, críticos o traumáticos que pueden afectar la salud física, emocional y mental de las personas que atraviesan situaciones de duelo.

Lazarus y Folkman (1984) han observado que, tanto en el campo de la biología como en la medicina, se suele definir al estrés como el aumento de intensidad de la respuesta de un individuo que está frente a una situación que considera como amenazante. Los autores hacen referencia a las diferentes características del sujeto, por un lado, y a la naturaleza del medio, por el otro. "El estrés psicológico es una relación particular entre el individuo y el entorno que es evaluado por éste como amenazante o desbordante de sus recursos y que pone en peligro su bienestar. El afrontamiento implica un conjunto de esfuerzos cognitivos y conductuales constantemente cambiantes que se desarrollan para manejar las demandas específicas externas y/o internas que son evaluadas como excedentes o desbordantes de los recursos del individuo"(Lazarus y Folkman, 1986, p.164).

Desde una perspectiva relacional, el estrés psicológico es el resultado de la relación entre el sujeto y su entorno: según sea la evaluación que el sujeto haga de la situación como amenazante o desbordante de sus propios recursos, es que sentirá o no que la situación puede poner en peligro su bienestar personal. Para Lazarus y Folkman (1984), el afrontamiento es un proceso a través del cual la persona maneja las demandas de la relación individuo-ambiente que éste evalúa como estresantes, y las emociones que la situación le genera.

Los autores antedichos señalan que el proceso de afrontamiento tiene tres rasgos claves: a) lo que el individuo hace realmente, b) el contexto determinado, y c) los modos en que puede ir cambiando la conducta a medida que se desarrolla la situación estresante o que se pasa de una situación a otra. Distinguen dos tipos de afrontamiento: a) centrado en el problema, orientado a hacer algo para alterar la fuente del estrés y, b) centrado en la emoción, orientado a reducir o manejar el malestar emocional que es asociado a una situación determinada. En el primer tipo de afrontamiento, centrado en el problema, existe la creencia de que se puede hacer algo constructivo; mientras que en el afrontamiento centrado en la emoción subyace la creencia acerca de que el estresor puede o debe ser desafiado.

El afrontamiento implica un conjunto de estrategias cognitivas, conductuales y emocionales que amenazan o superan los recursos del sujeto. Se diferencian formas de afrontamiento evitativas como el fantasear o no pensar en el problema; formas de afrontamiento activas como buscar apoyo instrumental; formas de afrontamiento centradas en las emociones como ocultar o suprimir sentimientos y formas de afrontamiento centradas en el problema como el desarrollar un plan de acción (Basabe, Páez; Usieto, Paicheler y Descahamps,1996).

Para Folkman et al., (1997), la afectividad positiva tiene un sentido adaptativo en el duelo, tanto en quienes brindan cuidados especiales a sus seres queridos antes de la muerte como en quienes afrontan un duelo posterior a la pérdida de su familiar. Endler y Parker (1990), consideran la utilidad del apoyo social en el duelo ya que, por medio de éste, el deudo puede buscar alivio y consuelo en los demás, focalizando su atención en el problema que debe enfrentar, a partir de los consejos que pide y recibe de los demás. También podrállevar a cabo un afrontamiento evitativo, visitando a amigos como manera de evadir la confrontación con su aflicción y con los sentimientos de desesperación que pueden surgir ante la pérdida de un familiar.

Attig (2007) destaca la importancia de las creencias en relación a su influencia en el afrontamiento de los duelos, ya que éstas producen gran impacto en lo que las personas sienten, en la evaluación de sus sentimientos, en la elección de la expresión adecuada y en las elecciones de sus acciones, reacciones e interacciones con los demás. Considera que las creencias espirituales son los medios principales de afrontamiento cognitivo de la realidad, ya que las capacidades de la mente y del espíritu orientan a las personas dentro de su realidad, dando sustento al sentido que prima en su vida. Las personas poseen mecanismos de afrontamiento emocional, conductual 
y social, pero las creencias tienen mayor influencia a través del impacto que producen sobre los sentimientos, sobre la evaluación de éstos y sobre las elecciones de vida personal. El afrontamiento a través de las creencias ayuda a las personas a orientarse en la realidad a través de conceptos y creencias sobre el mundo y sobre su realidad personal e interpersonal.

\section{RELIGIÓN Y ESPIRITUALIDAD EN EL DUELO}

Las creencias sirven, en general, para vivir en el mundo con un sentimiento de mayor confianza y seguridad.Como bien señalan Silver y Wortman (1988), algunas personas tienen algo de antemano, ya sea una religión, una orientación filosófica o una visión sobre la vida, que les posibilita afrontar sus experiencias de pérdida en forma casi inmediata. Por ello, es necesario que en las investigaciones se examine con claridad el rol que juegan estos recursos para los deudos como mecanismos de protección de los efectos negativos de las pérdidas.

Las religiones del mundo se ocupan de las transiciones y de las crisis más importantes de la vida de los seres humanos; y todas tienen algo para decir sobre el nacimiento, el envejecimiento, la formación de familias, las enfermedades, el dolor, el sufrimiento, los accidentes, las injusticias, las pérdidas, las tragedias y la muerte. Por ello, los distintos credos religiosos ofrecen teologías y rituales para los tipos de sucesos mencionados. Los símbolos, los rituales y las metáforas son parte central de la vida religiosa y generan nuevas formas, debido a que las situaciones atraviesan procesos de cambio social y cultural. Las nuevas técnicas de fertilización asistida, el trasplante de órganos, las prácticas de los "cuidados paliativos" y de ayuda para el "buen morir" son, entre otros, algunos de los temas que se han planteado en las últimas décadas como interrogantes éticos y morales para las distintas religiones a partir del gran avance y desarrollo tecnológico de la ciencia médica en general.

Las creencias espirituales relacionadas con temas como la vida, la muerte, el proceso de morir, el sentido de la vida, Dios, la inmortalidad y los valores significativos orientan a los hombres en la vida y en su modo de vivir. Las preguntas sobre el significado y el sentido de la vida se relacionan con el valor y el propósito de la misma, así como con preguntas acerca de por qué vivimos, cuál es el propósito de la vida humana individual, por qué existe el sufrimiento, cuál es el sentido del sufrimiento, por qué existe la muerte, por qué existen ciertos tipos de muerte presentes en el aquí y ahora, entre otras. Cuando las personas enfrentan la muerte y el duelo surgen preguntas sobre el sentido de la vida y de su existencia a posteriori de la pérdida del ser amado. Los deudos necesitan reaprender el mundo, reinterpretarlo y moldearlo de acuerdo a sus propios valores estéticos, religiosos y éticos encarnados en su vida a posteriori de la pérdida sufrida (Attig, 2003).

Una pérdida afectiva anterior, cuyo duelo no hubiera sido resuelto, podría sensibilizar a la persona en cuanto a los efectos que podría sufrir ante una pérdida futura. Si la persona pudo aprender y desarrollar en su infancia mecanismos de afrontamiento eficaces, contará con mayores recursos que le permitirán afrontar la pérdida actual y las pérdidas futuras. Si, en cambio, la persona fue incapaz de desarrollar mecanismos de afrontamiento en una temprana edad, entonces será más proclive a manifestar reacciones depresivas ante cualquier situación de pérdida de los seres queridos en los que solía apoyarse (Parkes \& Markus,1998).

Lo central de la religión y la espiritualidad son los sentimientos y las creencias de que hay fuerzas superiores al hombre que actúan en el universo, forzando a la capacidad humana más allá de su límite de comprensión. Boisen (1955), destaca que la religión y la teología tienden a cobrar sentido en los momentos en que uno se ve enfrentado a las realidades últimas de la vida y de la muerte. Entonces, aparecen símbolos, nuevas palabras e ideas que expresan el contacto de la persona con la realidad última a la que denomina "Dios". Tanto desde el campo de la psiquiatría como desde la teología, se señala que cuando el ser humano se ve enfrentado a situaciones límites busca otorgar sentido a algo "sagrado" en su vida, tratando de atribuir significados a la vida y a la muerte, basándose en visiones de Dios, de alguna deidad o de algún tipo de fuerza sobrenatural que lo supere y trascienda como ser humano.

Spilka ( 2005) afirma que para muchas personas religiosas, el encuentro con situaciones de estrés como 
enfermedades graves, muertes de seres queridos, injusticias, etc., confrontan con el sufrimiento y las limitaciones humanas; por ello, éstas tienden a orientarse y a estar más comprometidos con lo sagrado. Para ellas, la religión les ofrece modos de afrontar y de hallar soluciones a los problemas más graves de la vida. Quienes han adherido a un credo o a un camino espiritual contarán con creencias, valores, sentidos y prácticas religiosas que les permitirán anticipar y- tal vez- manejar situaciones críticas que se les pueden presentar a posteriori. La religión, así como la espiritualidad de las personas creyentes y practicantes pueden preceder a situaciones de crisis y servir para estructurar los modos en que dichas personas anticipen, interpreten y manejen situaciones críticas.

De todos modos, Pargament (1997) señala que las experiencias religiosas no están reservadas sólo para tiempos de crisis, y la religión no es el único modo de afrontamiento de situaciones de vida negativas. La cuestión es ver si la religión aparece como el modo de afrontamiento principal en tiempos de crisis o en momentos menos graves de la vida. Se ha podido observar que muchas personas que no han sido religiosas se volcaron hacia la religión después de atravesar alguna situación de crisis, una enfermedad personal, la enfermedad de un familiar, la pérdida de un ser querido, una catástrofe social o natural, al haber buscado respuestas y métodos que les permitieran aliviar y mitigar su dolor y malestar. Hay quienes, aunque habían sido creyentes y practicantes de un credo religioso, frente a alguna situación de vida negativa que consideraron difícil de superar, atravesaron momentos de desconfianza o dudas de su fe religiosa, desconfianza hacia Dios, hacia su congregación religiosa, hacia el clérigo o acerca de la eficacia de su afrontamiento religioso. Por diversos motivos, algunas personas religiosas abandonan la religión o su credo en medio de situaciones problemáticas cuando sienten que los recursos religiosos no les otorgan respuestas significativas o satisfactorias. Otras personas, después de dudar y atravesar momentos conflictivos vuelven a confiar en su fe, en Dios, en algún poder superior o divinidad y salen más fortalecidos de su crisis religiosa, afirmándose de manera más plena en su credo y en su sentimiento religioso espiritual. Mientras que algunos, al no encontrar sentido dentro de su credo de origen, atraviesan procesos de conversión religiosa a otro credo o tradición espiritual que les provee otras creencias, métodos, rituales y sistemas de atribución de sentido que les resultan de mayor significación y eficacia para el afrontamiento de la situación negativa que deben enfrentar.

\section{AFRONTAMIENTO RELIGIOSO ESPIRITUAL DE LA PÉRDIDA}

Pargament (1997) desarrolló el concepto de afrontamiento religioso espiritual basándose en la teoría del afrontamiento de Lazarus y Folkman (1984), dando especial importancia a la cosmovisión y al sistema de creencias que cada individuo posee y a su función de orientación en el mundo y en las situaciones específicas que cotidianamente atraviesa. El autor retoma también los conceptos de Frankl $(1994,2004)$ sobre el sentido de la vida como algo profundamente religioso y trascendental que debe ser descubierto por cada persona.

El afrontamiento religioso espiritual alude a una búsqueda de sentido como fuerza que guía la vida, dirigiendo a las personas hacia diferentes caminos. Tal búsqueda no tiene un objetivo universal, ya que puede orientarsehaciaobjetosmateriales, fisicos,psicológicos, sociales como espirituales, que pueden ser buenos o malos. Frente a situaciones críticas, muchas veces, las personas niegan y evitan la confrontación con su propia mortalidad y con su vulnerabilidad, buscando proteger sus valores; por lo que la conservación del sentido es una tendencia inicial que se manifiesta en las situaciones más amenazadoras (Pargament,1997).

La búsqueda de sentido alude a dos preguntas centrales sobre el sentido del suceso negativo en general, y al sentido para uno mismo. Asimismo, refiere a los modos en que el suceso puede afectar al individuo: si le interesa o si debería interesarle, si se siente implicado en la situación, si percibe que debería estarlo; si siente necesidad de actuar; si piensa que el suceso negativo podría afectar sus objetivos, sus normas, las creencias sobre sí mismo y sobre su entorno. A veces, las personas niegan las amenazas que representan ciertos sucesos negativos, persistiendo en mantener su modo de vida cotidiano de cualquier manera, hasta que se dan cuenta que eso no tiene más sentido. La nueva tarea será la de reconstruir y/o buscar 
nuevos valores y sentidos, nuevas creencias, caminos y modos de vivir; por lo que, según Pargament (1997), se deberá iniciar un proceso que implicará llevar a cabo una reconstrucción del sentido de la vida como tarea de afrontamiento.

Es más factible acceder a un tipo de afrontamiento religioso espiritual cuando los recursos de la religión están a disposición de la persona, ya que forman parte del sistema de creencias del individuo, orientando su vida y su conducta en la vida cotidiana. Sin embargo, aunque muchas personas cuenten con prácticas y creencias religiosas, en ocasiones podrán sentir que su fe ya no les sirve, que es insuficiente y/o que sus recursos religiosos no son adecuados para ayudarlos a resolver los problemas que se les presentan (Pargament, 1997).

Las situaciones de vida negativas o estresantes pueden movilizar respuestas de afrontamiento religioso espiritual como de otras formas de afrontamiento no religioso. Es importante observar si la persona utiliza estrategias de afrontamiento no religioso en forma exclusiva o complementaria al afrontamiento religioso espiritual. El modo de afrontamiento dependerá de la disponibilidad de recursos religiosos espirituales que la persona tenga a su disposición, del sistema de creencias religiosas que haya elegido previamente, el cual actuará como orientador para la atribución de sentidos. Todo esto permitirá enfrentar de manera eficaz las situaciones de la vida cotidiana así como las situaciones de estrés, usando algunos o todos los recursos que la religión provee, siempre que éstos estén o hayan estado al alcance previamente (Pargament,1997).

\section{ESTILOS DE AFRONTAMIENTO RELIGIOSO ESPIRITUAL}

Pargament (1997) describe tres estilos de afrontamiento religioso espiritual que las personas religiosas de distintos credos pueden utilizar: autónomo, evitativo y colaborador. Estas estrategias divergen en función del sentido de control que la persona se atribuye a sí misma y/o a la divinidad, por lo que se pueden observar las siguientes posibilidades:

a) el control puede estar centrado en la persona a partir de la creencia que ésta tenga sobre la disponibilidad de contar con elementos, recursos y/o herramientas propias que le permitan resolver conflictos y/o situaciones problemáticas por sí misma;

b) el control puede estar centrado en Dios o en distintos tipos de divinidades a partir de lo cual, la persona podrá sentir que la responsabilidad final reside en Dios o en la divinidad. En este tipo de resolución de problemas es frecuente observar una actitud pasiva donde la persona suele dejar la situación "en manos de Dios" o en otra fuerza exterior, sin hacer nada por ella misma;

c) el control puede estar centrado en los esfuerzos de la persona quien, a través de su práctica y su fe religiosa podrá pedir la guía y la intervención divina, buscando influenciar la situación de modo tal que se cumplan sus pedidos o deseos;

d) el control puede estar centrado en un trabajo conjunto de la persona con Dios y/o la divinidad. La persona podrá sentir que trabaja junto a Dios -u otra divinidad- para resolver las situaciones problemáticas. El sujeto religioso sentirá que no está solo ni que la divinidad actúa por sí misma, ya que confía en la posibilidad de un trabajo conjunto de colaboración entre ambos, y en la responsabilidad compartida con Dios o con otra divinidad .

Para Pargament (1997), el estilo de afrontamiento religioso colaborador se asocia a un mayor nivel de competencia personal y a diversos beneficios y efectos positivos como: una menor cantidad de síntomas de enfermedad, menores niveles de ansiedad y menores sentimientos de culpa asociados a un estado de gracia y de perdón de uno mismo por los propios pecados cometidos. En cambio, el estilo de afrontamiento autónomo resultó ser más exitoso en temas asociados con la abstinencia respecto del alcohol; mientras que el estilo evitativo, en el que el individuo puede dejar la situación problemática en manos de Dios y/o de otros poderes superiores, es el más utilizado -en general- en situaciones negativas en las que las personas religiosas sienten que tienen muy poco control sobre sucesos como guerras, inundaciones, catástrofes naturales, etc. En estudios posteriores se encontró una relación de correspondencia del estilo evitativo con sensaciones de bajo control personal sobre la situación, con 
sentimientos de baja autoestima, con mayores niveles de pasividad y de dependencia mayor de la persona hacia un poder exterior (Spilka, Hood, et al., 2003).

En este sentido, Pargament (1997) señala el hecho de que el estilo de afrontamiento evitativo ha sido considerado como un tipo de religiosidad muy criticada por una importante cantidad de psicólogos. Aunque el autor destaca que en algunos casos, las personas religiosas utilizan el estilo de afrontamiento evitativo sin caer en sensaciones de desesperanza al mantener su confianza en Dios, en poderes superiores y/o en sí mismos, pensando que serán ayudados por la divinidad para la resolución de situaciones problemáticas. Es distinto sentirse solo en manos del destino, que confiar en Dios y/o en ciertas divinidades, invocarlos, dirigirse a éstos para pedirles ayuda $\mathrm{y}$ sentir que influyen de algún modo positivo en las situaciones de estrés que se está enfrentando, como también en la resolución de tales sucesos negativos y/o problemáticos. Por esto, el estilo de afrontamiento evitativo puede ser beneficioso- siempre y cuando- la persona, a pesar de sentir que la situación escapa a su control, no pierda su fe ni su esperanza y confíe en el poder de Dios, de las divinidades o en otros poderes superiores. Esta actitud se basa en la confianza y en la fe de la persona religiosa que sabe que a través de su práctica espiritual, Dios o los seres superiores podrán guiarlo y/o ayudarlo a pensar y/o a resolver las situaciones negativas que está atravesando. Hacer plegarias peticionales dirigidas a Dios y/o a otros poderes superiores no implica establecer una situación de dependencia hacia un poder externo, ni asumir una actitud pasiva para la resolución de problemas. Las personas religiosas pueden asumir actitudes activas aún cuando hagan plegarias con pedidos a Dios o a otras divinidades, ya que confían en sí mismos, en su fe y en la eficacia de su práctica religiosa/ espiritual (Pargament, 1997).

En su Proyecto sobre Religion y Afrontamiento, Pargament, Ensing et al.,(1990) evaluaron el apoyo religioso espiritual través de una escala de actividades de afrontamiento cuyos items reflejan diversos componentes del apoyo: a) el reaseguro emocional como la "confianza en que Dios no dejaría que me suceda nada terrible"; b) la relación espiritual cercana como la "búsqueda de amor y cuidado divino", y c) la guía para la resolución de problemas en términos de "Dios me muestra cómo manejarme en cada situación". Las personas que llevaron a cabo un tipo de afrontamiento basado en lo espiritual señalaron haber tenido una mejor adaptación a las situaciones difíciles que tuvieron que enfrentar. Sin embargo, el afrontamiento basado en lo espiritual y el estilo colaborador -en el que la persona trabaja junto con la divinidad para la resolución de sus problemas- surgió como el predictor más fuerte de efectos positivos en la salud, en comparación con quienes utilizaron otra modalidad de afrontamiento. La relación que la persona religiosa entabla con Dios o con otras divinidades en tiempos de crisis resulta beneficiosa ya que permite que éstas se sientan acompañadas simbólicamente por la presencia divina, sagrada y poderosa que no las deja solas.

\section{EFECTOS POSITIVOS Y NEGATIVOS DE LA RELIGIÓN}

Pargament (1997) discute el argumento de Freud (1927/1961) de que la religión es simplemente una defensa que actúa en contra de la confrontación de la realidad. Aún hoy, esta proposición es sostenida por muchos psicólogos, psicoanalistas y profesionales de la salud mental. Hay coincidencia en cuanto a que la religión puede actuar de manera negativa en los casos en que es usada para negar la realidad, para actuar de manera evitativa y pasiva en la resolución de problemas, o en los casos de individuos que mantienen posturas pasivas frente a Dios, esperando algún tipo de milagro o una resolución mágica de sus dificultades. Sin embargo, como indican Pargament y Parks (1995), la concepción de que la religión sólo produce efectos negativos forma parte de estereotipos ya que, tanto la religión como la espiritualidad, como sistemas multidimensionales y complejos, se refieren a distintos modos de afrontamiento de sucesos negativos de la vida. La religión como la espiritualidad se dirigen hacia lo sagrado, hacia la promoción de valores éticos y morales, hacia la búsqueda de sentido y significados para temas tan misteriosos como el origen de la vida, el sufrimiento, las enfermedades y la muerte. La ciencia no brinda respuestas finales a dichas cuestiones; y cuando las da, éstas son parciales o imposibles de probar y de comprobar. 
Koenig et al., (2001) plantean que, en ocasiones, la religión puede producir patología, en particular cuando se refiere a negaciones que promueven distintos grupos religiosos ortodoxos o fundamentalistas de diversos credos. Las religiones pueden producir distorsiones o contradicciones en sus fieles en cuanto a maneras de actuar, pensar, sentir y/o a la expresión de sus sentimientos. En este sentido, la religión puede actuar en forma negativa a través de creencias o modos de apreciación de la realidad y de diversos hechos: a) cuando una enfermedad es vista como un castigo divino por los pecados cometidos; b) cuando no se busca o no se acepta la ayuda de la medicina para el tratamiento de enfermedades, y en cambio, se quiere resolver las situaciones por medio exclusivamente religiosos o espirituales; c) al interpretar que los conflictos personales se deben sólo a la intromisión del demonio o del diablo en el cuerpo de una persona, por lo que se deja de recurrir a diagnósticos y tratamientos médicos adecuados que pueden mejorar la salud; d) cuando se deja la solución sólo en manos de Dios y se recurre a modos de afrontamiento pasivos, evitativos o de negación de la realidad.

Pargament (1997) reseña que quienes se refieren a los efectos negativos de la religión en tiempos de crisis destacan que ésta no ha sido beneficiosa sino más bien dañina; y en general, los señalamientos suelen ser dirigidos hacia miembros de la congregación o al grupo espiritual y/o al representante del mismo. Con frecuencia, las personas que han sufrido una situación negativa suelen sentir que han sido abandonados en momentos críticos de su vida, por lo que sus quejas suelen referirse al haber sido abandonados, a no haber sido escuchados por Dios, y/o a que la divinidad no respondió sus plegarias, etc. Tales quejas pueden estar acompañadas de sentimientos de gran insatisfacción, resentimiento $\mathrm{y} / \mathrm{o}$ descontento religioso dirigidos hacia los pares o hacia el representante del propio credo, hacia Dios o hacia cualquier forma de deidad en la que se haya creído previamente. Estas personas podrán presentar problemas de salud mental, estados de ánimos negativos o una resolución defectuosa de situaciones críticas. El enojo hacia la religión es la primera reacción del afrontamiento religioso, aunque en ocasiones, los efectos del descontento religioso puede ser más duradero y no ser integrado como un momento dentro de un proceso de cambio personal. En estas situaciones, se suele atribuir a Dios los efectos negativos que se sufren, como si fueran un tipo de castigo divino por los pecados cometidos o por haber resuelto mal los problemas que se tuvo que enfrentar.

\section{AFRONTAMIENTO RELIGIOSO ESPIRITUAL POSITIVO Y NEGATIVO}

Pargament, Koenig et al., (2000) distinguen 22 modos de afrontamiento religioso /espiritual dentro de los que diferencian conductas positivas y negativas. En el tipo de afrontamiento religioso positivo se incluyeron items tales como: la apreciación de Dios como benevolente, la tentativa de colaborar con Dios, la búsqueda de una relación de mayor contacto con Dios, la búsqueda de apoyo religioso espiritual de parte de la congregación religiosa y/o del representante de la misma, la confianza en Dios, el ofrecer ayuda espiritual a otras personas, la purificación religiosa por medio de plegarias, oraciones, de pedir y otorgar perdón a otros.

En el afrontamiento religioso negativo se incluyeron creencias sobre: Dios como un ser que castiga por medio de enfermedades, las fuerzas demoníacas relacionadas con una salud pobre, las experiencias de descontento emocional y la sensación de interferencias en la relación con Dios.

Pargament y Brant (1988), han sugerido realizar algún tipo de análisis que pueda determinar si la religión actúa como fuerza positiva, negativa o simplemente irrelevante cuando se considera la adaptación a sucesos de vida negativos, estresantes y/o traumáticos. Al referirse a efectos en la salud, los autores mencionan la salud física relacionada a factores tales como: la ausencia de síntomas, la cantidad de veces en que la persona estuvo hospitalizada, las tasas de mortalidad, entre otros. En los efectos positivos relacionados a la salud mental se refieren a la eficacia de los tipos de afrontamiento, a la satisfacción con la vida, a niveles de depresión y de ansiedad. En lo que hace a la salud religiosa y/o espiritual, incluyen cambios en el individuo, en la percepción del contacto con Dios y en el crecimiento espiritual como resultado de una modalidad eficaz del proceso de afrontamiento del suceso de vida negativo que se ha tenido que enfrentar. 
Pargament (1997) se pregunta si el tipo de afrontamiento religioso espiritual tiene algún elemento único que actúe como un factor que puede contribuir a la adaptación, más allá de los métodos y actividades de afrontamiento no religiosos utilizados. Pargament, Smith y Koenig (1996) crearon una escala breve para medir el afrontamiento religioso denominada BriefRCOPE (Escala abreviada de Afrontamiento religioso), basada en dos tipos de patrones de afrontamiento religioso:

1) Métodos de afrontamiento positivo: que incluyen el apoyo religioso espiritual, el estilo colaborador, el reencuadre o la resignificación religiosa benevolente.

2) Métodos de afrontamiento negativo: referidos al descontento con la congregación, con los pares religiosos y/o con el representante del credo y con la resignificación religiosa negativa.

El Afrontamiento Religioso Positivo agrupa ítems que incluyen al apoyo espiritual, al modo del afrontamiento de estilo colaborador, al reencuadre y a la resignificación religiosa positiva. El Afrontamiento ReligiosoNegativoincluyeeldolorespiritual,elmalestar y la frustración. Una subescala integra el descontento con la iglesia y/o con Dios, la resignificación del hecho como un tipo de castigo divino y las plegarias como modo de retribución divina.

Pargament (1997) señala que lo más importante es poder observar si a través del modo de afrontamiento la persona está yendo en una dirección positiva que le permita alcanzar efectos positivos, y si está usando recursos que la ayuden afrontar la situación de estrés. El sufrimiento se hace más tolerable si la persona logra hallar explicaciones que otorguen algún sentido al momento dificil que está atravesando. Las creencias religiosas permiten reafirmar que la vida tiene algún sentido, a pesar de todo lo negativo que se deba afrontar. Las situaciones de pérdida por muerte de un ser querido pueden representar una amenaza a las creencias y al sistema de valores de cada persona, incluso para el caso de personas creyentes y practicantes de algún credo religioso; y pueden hacer que surjan preguntas y cuestionamientos sobre lo que éstos creían acerca de sí mismos, sobre el suceso en cuestión y sobre la índole de lo sagrado sobre el cual habían depositado su fe. Diversos estudios empíricos muestran cómo las personas religiosas perseveran para mantener sus creencias y prácticas religiosas en momentos de gran estrés y que, después de haber atravesado el momento crítico de su vida, mantienen su fe religiosa y la sienten más fortalecida (Pargament,1997).

La pregunta del rabino Kushner (1981) sobre el por qué le suceden cosas negativas o malas a la gente buena es un buen ejemplo de lo mencionado anteriormente. Muchas veces, las personas religiosas, ante situaciones negativas, se vuelcan contra su credo religioso, contra su Dios o su congregación, rechazando por entero sus creencias religiosas, volviéndose ateos, agnósticos o antirreligiosos. Otras, en cambio, podrán reconstruir su sistema de creencias atravesando procesos de profunda transformación espiritual y/o de conversión religiosa hacia otro credo religioso en el que encuentran más respuestas que les brinden sentido y significación a lo vivido y a su vida en general (Pargament,1997).

\section{ESTUDIO DE CASO}

En mi investigación de Tesis Doctoral sobre " $L a$ influencia de las creencias y las prácticas religiosas espirituales en el afrontamiento de la pérdida -por muerte- de un ser querido", surgieron diferentes manifestaciones relacionadas con la participación de los deudos en rituales funerarios y de duelo, como también sobre la importancia del apoyo social y religioso recibido y/o brindado en el duelo. A continuación, nos referiremos a la modalidad de afrontamiento religioso espiritual utilizada por una participante con adhesión y participación en el credo católico que enfrentó la pérdida por muerte de su hermana menor. A fines de preservar la identidad y mantener el anonimato, la participante fue apodada María por la autora del estudio (Yoffe,2012a).

Se llevaron a cabo dos entrevistas en profundidad con dicho sujeto hacia finales del segundo año de duelo, en las cuales se mostró con gran interés hacia la temática propuesta, participando activamente y agradeciendo la posibilidad de poder conversar sobre su pérdida, su religiosidad y espiritualidad como los recursos de afrontamiento del duelo. 
Al momento de las entrevistas, la participante (de 68 años de edad) refirió que su nivel de estudios era universitario y su profesión Licenciada en Letras. Asimismo, informó que desde su juventud trabaja como profesora de nivel terciario y universitario, que realizó estudios religiosos de catecismo del credo católico romano, habiendo trabajado como catecista durante su juventud en la parroquia de la escuela donde cursó sus estudios primarios y secundarios. La participante se autodefinió como "una persona religiosa muy creyente y practicante católica”.

Familia de origen: los abuelos paternos y maternos de María emigraron de Italia y vivieron en Argentina hasta el momento de la muerte de cada uno de éstos. Su madre y su padre (argentinos ambos) estaban fallecidos al momento del estudio. Los miembros de la familia de origen habían sido todos creyentes y practicantes católicos. Maria y su hermana menor (de nacionalidad argentina) concurrieron a una escuela de monjas donde recibieron educación religiosa católica. La participante informó que ambas realizaban durante su infancia y adolescencia actividades religiosas como lectura de textos, oraciones y plegarias católicas en el hogar junto a su madre.

Familia actual: la participante se casó a los treinta años con un hombre religioso y practicante de su credo. $\mathrm{Al}$ momento de las entrevistas, la pareja matrimonial llevaba veintinueve años de casados y tenían una hija de veintitrés años de edad.

Religiosidad: la participante se autodefinió como una persona de "mucha fe, muy religiosa y espiritual al mismo tiempo", que había estudiado catecismo y realizado prácticas católicas desde su infancia tanto en su hogar como en la escuela de monjas, la iglesia y en grupos de estudio de catecismo. En su juventud había enseñado catequesis en la parroquia de su escuela y, posteriormente comenzó a participar en misas y grupos de estudios del Movimiento de la Renovación Carismática. Comentó que en dichos espacios: "pude aprender a ponerme en contacto con Dios, a entregar mis defectos, a pedir con los demás lo que necesitaba junto a los demás que me acompañaban en mi búsqueda personal. Tratábamos temas que conversábamos y profundizábamos en ellos dialogando y rezando en conjunto."
Espiritualidad: Maria informó que en su proceso de búsqueda espiritual llevado a cabo en su adultez aprendió prácticas de sanación de la tradición japonesa del Reiki y de sanación con chakras (de tradiciones orientales ajenas a su credo). A partir esto, se consideraba a sí misma como "una catequista poco común que aportaba mis conocimientos y no vivía el catolicismo como algo pasivo de cumplimientos de rituales vacíos de espiritualidad". Destacó su actitud optimista y esperanzada ante la vida expresada a través de pensamientos y acciones como "si uno tiene fe, todo es posible" .

Duelo actual: la participante atravesó el duelo anticipado por la pérdida de su hermana menor fallecida a causa de cáncer de pecho con metástasis en huesos, seis meses después de la muerte de la madre de ambas.

Duelos previos: Maria sufrió las pérdidas repentinas de su padre y abuelos en la etapa de su juventud. La madre de Maria falleció a los 96 años de edad debido a un estado de vejez avanzada. La participante comentó en sus entrevistas que cuando ella tenía 66 años sufrió la pérdida anticipada de su progenitora que "era previsible dado que mi madre había estado enferma durante tres años, y su condición se había agravado luego de una caída en la que sufrió la fractura de pelvis". Durante el duelo anticipado, la participante cuidó a su madre, haciéndose cargo del mantenimiento de la casa de ésta, de los trámites de internación, como también de los tratamientos médicos y la hospitalización de su hermana ya enferma de cáncer de pecho. Poco después de la intervención quirúrgica por la fractura de pelvis, la madre de Maria entró en coma y falleció a los pocos días. La participante expresó al respecto:"Yo estaba sola con mi mamá cuando murió. Yo vi morir a todos: a mi abuelo, a mi papá tiempo atrás y en estos últimos tres años a mi mamá y a mi hermana." Comentó que ante la inminencia del fallecimiento de su madre, sintió mucha angustia y miedo, pero que no se permitió deprimirse porque debía seguir cuidando a su hermana enferma. El haber podido atravesar un duelo anticipado marcó gran diferencia con los duelos previos al permitirle despedirse del ser querido moribundo. Una médica le dijo:- "Ya no hay nada más para hacer dado que tu mamá está muy viejita. Hablále,ya aunque esté en coma 
te puede oir ." María le expresó su amor deciéndole: "fuiste una mamá de oro". Según la participante, el poder acompañar, brindar cuidados prácticos, afectivos y espirituales al ser querido enfermo le permitió "aceptar la muerte, ya que invoqué al Espiritu Santo que la ayudó a morir pronto y en paz. Yo sabía que había perdido a mi madre, pero también sabía que tenía que aceptarlo."

Psicoterapia: Maria nunca hizo psicoterapia, aunque acompañó a su hermana menor a entrevistas psicoterapéuticas luego de que ésta recibiera el diagnóstico de un tumor maligno de cáncer de pecho. A posteriori del fallecimiento de su hermana, la participante acudió al mismo profesional quien le indicó que hiciera yoga o Tai Chi para disminuir el estrés producto de sus duelos anticipados, considerando que Maria contaba con suficientes recursos personales y espirituales para afrontar sus pérdidas.

\section{DUELO ACTUAL : PÉRDIDA DE LA HERMANA}

Maria tenía 65 años cuando su hermana menor (de 61 años) falleció seis meses después de la muerte de la madre de ambas. En las entrevistas, la participante refirió que luego de la crisis económico- social sufrida en Argentina en el año 2001, su hermana había sufrido una grave crisis personal y económica, a partir de la cual desarrolló micro-calcificaciones y nódulos en ambos pechos, pero sin haber realizado ningún tratamiento al respecto. Cuando la madre estaba hospitalizada, la hermana de Maria realizó nuevos estudios médicos en los que se le diagnosticó un tumor de cáncer de pecho maligno avanzado. Luego de ésto inició tratamientos oncológicos (cirugía, quimioterapia y radioterapia) que permitieron una mejoría de su estado; pero la depresión posterior a la muerte de su progenitora produjo el agravamiento de las enfermedades físicas y psiquicas que padecía.

La participante informó que se hizo cargo del cuidado de su hermana durante los tratamientos oncológicos y hospitalización, mientras que -al mismo tiempo- cuidaba a su madre internada a causa de la fractura de pelvis sufrida tras una caída en el hogar. Sobre esto, comentó: "Mi hermana canalizaba toda su energía a través de su trabajo y se sentía como un apéndice de mi madre . Por eso, nunca habia tenido pareja ni amigos. El deterioro físico y la muerte de mi mamá le hicieron sentir una falta de sentido de la vida y la falta de motivación para seguir viviendo. La depresión que tenía le produjo un agravamiento de su enfermedad cancerígena, llevándola a la muerte."

Maria sufrió dos pérdidas anticipadas- la de su madre y la de su hermana menor- muy seguidas en el tiempo, lo cual dificultó poder distinguir los sentimientos relacionados con cada una de éstas. De todos modos, refirió que frente a la inminencia del fallecimiento de su madre había sentido mucha angustia y miedo: "sabía que había perdido a mi madre, pero también sabía que tenía que aceptarlo.” Ante el fallecimiento de su hermana registró sentimientos de tristeza, vacío y soledad ante la falta de miembros de su familia de origen, expresando al respecto: "Se me caían las lágrimas todo el tiempo. Fui sintiendo que había perdido a mis dos pilares. Después me di cuenta que me había aferrado demasiado a mi hija, esperando que me diera lo que me daba mi hermana afectivamente."

La participante informó que le había sido más fácil aceptar la muerte de su madre (debido a su avanzada edad), que aceptar la pérdida de su hermana menor porque "al ser jóven, podría haber vivido más tiempo". Lo corroborado en este sentido coincide con lo que Lazarus y Folkman (1987) señalan acerca de la disrupción de la cronología vital como un aspecto de importancia en la agudización del estrés y el malestar en el duelo por la pérdida de un ser querido. De todos modos, el haber podido despedirse, acompañarla a morir y haber podido realizar prácticas religiosas facilitó su afrontamiento de la muerte y pérdida del ser querido. Cuando sentía tristeza, Maria pensaba: "Mi hermana está mejor en el otro plano donde su alma está con el alma de mis seres queridos, en otro plano donde uno sigue vivo espiritualmente". Al respecto, fueron referidos sentimientos de alivio y bienestar personal y espiritual producto de haber podido atravesar un duelo anticipado, de tener pensamientos positivos y una intensa fe religiosa personal. Todo lo cual, redundó en la presencia de sentimientos de calma y paz, en la disminución del malestar y aflicción en el duelo frente al vacio por las dos pérdidas sufridas. 


\section{AFRONTAMIENTO COGNITIVO: CREENCIAS RELIGIOSAS ESPIRITUALES EN EL DUELO}

En sus entrevistas Maria refirió su adhesión a las creencias católicas sobre Dios como ser benevolente y proveedor, a su fe en el inmenso poder de Cristo y del Espíritu Santo. También destacó su gran devoción hacia la Virgen María y a diversos santos, en particular, a San Benito de Palermo. Acerca de sus creencias religiosas comentó: "Dios es amor, es una energia vital que corre por las venas. Dios es y fue mi sostén y mi apoyo en la vida y en mis duelos..[..] Dios me iba poniendo en las manos lo que yo necesitaba cuando mi madre y hermana enfermaron.[..] Podía sentir la presencia de Dios a través del Espiritu Santo.[..] Dios me iba poniendo en situaciones que podía resolver y donde yo atraía lo que iba necesitando." Como devota de la Virgen María, consideraba que era "la madre de todos los creyentes", y por eso, le rezaba mucho cuando su madre y hermana enfermaron, pidiéndole por la curación de ambas. Sobre su devoción hacia los santos expresó: "Cada santo tiene su don y su carisma .Los santos son la comunión y la energía de quienes se fueron que nos ayudan cuando rezamos ya que interceden con nuestros pedidos para que los alcancemos." La fe en el Espíritu Santo se intensificó antes del duelo a partir de su participación en grupos de oración y misas de sanación del Movimiento Carismático en su juventud: "En los grupos carismáticos me enseñaron la fe. Yo iba a misas dadas por sacerdotes carismáticos en las cuales vivía y sentía mucha emoción y paz. El contacto con Dios era más directo y personal. Yo siempre pido la ayuda del Espiritu Santo, lo invoco, y aunque se tarde, se produce. Tengo fe en lo que dice el Evangelio: 'Pide y se os dará; ' 'llama y se os abrirá.'Yo aprendí a pedir y a tener fe en lo que pedía y en la búsqueda personal."

En el duelo anticipado, María rezaba con fervor pidiendo por la sanación de sus seres queridos: madre y hermana. Asimismo, refirió en sus entrevistas que su sentimiento de religiosidad y su fe en Dios y en sí misma, asociados a la esperanza y al pensamiento positivo fueron los recursos que le permitieron afrontar las pérdidas de sus familiares. Al respecto, destacó: "Cuando vivís la fe, confiás en que lo que pedís y ya lo estás viviendo. Es la palabra de Dios que te llega .Yo tengo un pensamiento muy positivo a través del cual pienso que todas las cosas se solucionan. Desde ahí, me aferro a la esperanza."
La participante refirió adhesión a las creencias cristianas sobre la inmortalidad y la vida del alma a posteriori de la muerte, señalando que a partir de sus estudios sobre budismo tibetano también adherió a las creencias budistas sobre el karma y la reencarnación. Acerca de ello, comentó: "Mis estudios de budismo me ayudaron a integrar distintas creencias religiosas de otro credo distinto al mío de origen que me ayudaron en mi duelo. Cuando no evolucionamos, nos enfermamos para aprender y seguir nuestra evolución a través del sufrimiento. Las enfermedades son medios para purificar el karma negativo y aprender lo que no pudimos a causa de factores como la ignorancia". Refirió al respecto: "Yo pude entender que las enfermedades son el lenguaje del cuerpo cuando la mente no puede verbalizar lo que le está pasando. La enfermedad es un despertador de conciencia: cuando no evolucionamos en un área, enfermamos para aprender. Cuando uno enferma y siente dolor, pero no entiende por qué y no encuentra sentido, sigue sufriendo. Es necesario tomar conciencia de las dificultades para comprender lo que el cuerpo está expresando. Si no se evita el dolor, se podrá encontrar esperanza de poder superarlo." En este caso, las creencias budistas permitieron ampliar la cosmovisión religiosa del sujeto religioso quien pudo así atribuir sentidos a las enfermedades físicas y psicológicas del ser querido. También fueron destacadas las creencias sobre el dolor y el sufrimiento del siguiente modo: "Yo veo, analizo el dolor y puedo encontrar esperanza. No me quedo pegada al dolor. Cuando no podés atribuir sentido al dolor ni a la vida, continúas sufriendo. Para mi hermana, su enfermedad, su dolor y su propia vida ya no tenían sentido después que murió mi mamá. Al no poder desarrollar fe ni esperanza en su curación, no logró superar sus enfermedades. La base de sus problemas de salud eran sus problemas psicológicos expresados en los distintos órdenes de su vida:" Según la participante, su hermana no había podido aprender el valor positivo de la vida y se había dirigido hacia valores extrínsecos y materiales como los de alcanzar fama, éxito y dinero para mantener económicamente a la madre, dejando de lado su propia evolución espiritual. Las dudas y la falta de fe religiosa junto a sentimientos de incertidumbre fueron factores que causaron y agravaron las enfermedades de su hermana, llevándola a la muerte. Lo referido es coincidente con lo que señala el Padre Betancour sobre: "La 
enfermedad puede conducir a la angustia, al repliegue sobre sí mismo, a veces incluso a la desesperación y a la rebelión contra Dios. Puede hacer a la persona más madura, ayudarla a discernir en su vida lo que no es esencial para volverse hacia lo que es. Con mucha frecuencia, la enfermedad empuja a una búsqueda de Dios, a un retorno a El.” (Betancour, 2005, p. 137).

La participante comentó que a partir de su búsqueda espiritual pudo desarrollar una mentalidad religiosa "abierta y nada dogmática". Las lecturas sobre temas de sanación cristiana, budismo tibetano y fisica cuántica le permitieron integrar conocimientos de la ciencia a las concepciones religiosas del catolicismo y del budismo. A partir de ello pudo realizar un proceso de sincretismo de creencias religiosas de su credo y de tradiciones espirituales orientales, aunque sin dejar de lado sus creencias católicas. Todo lo cual le posibilitó desarrollar " una conexión entre el cuerpo, la mente y el espiritu y el desarrollo de una mentalidad más abierta y ecuménica de respeto e integración de todas las religiones." Lo hallado coincide con lo señalado por Overberg (2002), acerca del reconocimiento del sufrimiento y el dolor, que -cualquiera sea su causapuede llevarnos a una madurez más profunda y a una sabiduría, como también pueda conducir a un quiebre del espíritu humano. En el caso de la hermana de María, el inmenso dolor, el sufrimiento y la desesperanza ante la pérdida de la madre produjo un agravamiento de la depresión que sufría, y de su enfermedad oncológica, que la condujo a la muerte.

La participante destacó que sus creencias religiosas espirituales fueron recursos de afrontamiento cognitivo de tono positivo que generaron una visión más optimista del mundo y de la vida, y una sensación de control sobre los hechos negativos relacionados con las enfermedades y los cuidados de su familiar enfermo, tanto en el duelo anticipado como a posteriori de la pérdida del ser querido. Así, como mujer católica manifestó: "Yo estuve todo el tiempo dedicada a mi hermana, sólo paraba para dormir. Estaba todo el día con ella cuando estuvo internada unos meses, porque la operaron varias veces de la columna.Yo le hacía la comida macrobiótica para su tratamiento contra el cáncer. Pudo morir sin sufrimiento y sin tener que darle morfina. Fue bueno verla irse en paz acompañada por mí, por mi hija y por nuestra amiga catequista que había estado presente todo el tiempo ayudándonos a las dos. Estuvo acompañada por todos nosotros, $y$ por sacerdotes. Así pudo sentir hasta el final de su vida el amor de todos hacia ella." Lo hallado en ese sentido coincide con lo que Folkman et al.,(1997), destaca sobre la afectividad positiva que tiene un sentido adaptativo en el duelo, tanto en quienes brindan cuidados especiales a sus seres queridos antes de la muerte, como en quienes afrontan un duelo por la pérdida de un familiar.

En las entrevistas, la participante relató un sueño en el cual su hermana le decía: "Yo estoy en un lugar de sol donde me cuidan mucho. Yo me dediqué a otras cosas y tal vez no supe ver el camino a la verdad; pero estoy contenta porque sé que vos estás en el camino". Este sueño le produjo paz y alegría: "porque sentí que mi hermana estaba bien donde estaba". El mensaje positivo trasmitido por la hermana fue resignificado por la participante como una reafirmación de su elección de vida realizada desde la fe, a partir de una búsqueda espiritual y una dedicación religiosa complementaria a la de su vida como esposa y madre y a su vocación profesional. Fueron las creencias católicas sobre la esperanza, la fe religiosa y el optimismo los recursos que permitieron a la participante superar su dolor y el sufrimiento causado por las enfermedades, las múltiples cirugías y la posterior muerte de su hermana. Asimismo, la actitud positiva y la adhesión a las creencias de su credo de origen y a las del budismo tibetano permitieron buscar alivio -a través de distintas prácticas religiosas espirituales- del dolor físico, psíquico y espiritual del ser querido enfermo y del propio malestar del deudo en el duelo anticipado.

La participante destacó su actitud positiva, su fe y su esperanza como recursos que la ayudaron a aceptar las pérdidas de su madre y de su hermana, ocurridas en el término de sólo seis meses: "Las afirmaciones positivas me permitieron ir aceptando de a poco las pérdidas de mi mamá y de mi hermana. Empecé a decirme: 'esta etapa va a ser mejor, va a ser tan buena como las otras, y no tiene por qué no serlo'. Pude empezar a sentir que estaba sobre mis propios pies y me decía: "el pilar soy yo, estoy sobre mis talones y mi apoyo soy yo". Pargament (1997), afirma que el significado del sufrimiento en el catolicismo permite a la mayoría de los católicos conservar su fe, ya que los 
alienta a afrontar y a resolver las situaciones de vida negativas que enfrentan. En este caso se corroboró cómo la religión puede actuar en forma positiva al proveer creencias que permiten realizar procesos de atribución positiva a la pérdida y a las situaciones negativas presentes en el duelo. Wortmann, Silver y Kessler (1993) destacan que la presencia de un sistema de creencias permite predecir la salida de un duelo, ya que quienes poseen un sistema de creencias que incluya la posibilidad de muerte podrán sufrir un menor impacto negativo de la pérdida, una vez sobrevenida la misma. Esto marca una gran diferencia con las personas cuyo sistema de creencias no les permite acomodarse a la situación de pérdida al percibirla y vivirla como una "calamidad". Koenig et al.,(2001) plantean que la religión puede actuar en forma negativa a través de creencias o modos de apreciación de la realidad cuando la enfermedad es vista como un castigo divino por los pecados cometidos, cuando el sujeto no busca o no acepta la ayuda de la medicina para el tratamiento de enfermedades y quiere resolver las situaciones por medio exclusivamente religiosos o espirituales. En este caso no se hallaron creencias sobre las enfermedades causadas por la intromisión del demonio o del diablo en el cuerpo de la persona, ni se observó que la participante dejara de recurrir a diagnósticos y tratamientos médicos adecuados para mejorar su salud.

\section{AFRONTAMIENTOCONDUCTUAL: PRÁCTICAS RELIGIOSAS ESPIRITUALES EN EL DUELO}

De las entrevistas realizadas con María surgieron las siguientes prácticas religiosas realizadas en su duelo: lectura de textos sagrados, plegarias, meditación, sanación espiritual -healing- realizadas en forma frecuente antes y después de la muerte del ser querido y la participación en rituales funerarios. Hufford (2005) incluye las plegarias que se hacen para uno mismo -self prayer-y las que se hacen para el beneficio de demás junto a las prácticas de sanación -healing-, el Yoga, el Tai chi, el masaje, la meditación y la participación en grupos de oración entre las prácticas espirituales orientadas a la salud.

La participante comentó que desde pequeña solía realizar prácticas de su credo de origen como rezar novenas a los santos y el rosario en forma diaria junto a su madre y a su hermana porque sentía que "había que vivir en actitud de oración". Después de aprender budismo, integró esta práctica con la de meditación y rezaba "el Rosario como si estuviera meditando." La práctica de oración realizada durante el duelo anticipado de su madre y de su hermana le permitió afrontar los momentos difíciles de las internaciones, las intervenciones quirúrgicas y el agravamiento de las enfermedades de ambas. María refirió que hacía plegarias peticionales a Dios, a la Virgen María y al Espíritu Santo en las que pedía por el reestablecimiento del bienestar físico, emocional y espiritual de su hermana. En ocasiones, realizaba esta actividad junto a su hija adolescente, su amiga catequista y un sacerdote conocido de la familia. También hizo plegarias de sanación en compañía de familiares de mujeres internadas en el hospital oncológico. A posteriori, contó con la ayuda de pastores evangélicos con quienes rezó, pidiendo por una muerte en paz de su hermana moribunda.

Durante el duelo anticipado, la participante hizo "afirmaciones de salud" como modo de auto-sanación. Al mismo tiempo, realizó Reiki, (un tipo de sanación oriental con energía universal aplicada sobre los chakras o centros de energía) para sí y para ayudar a su hermana anímicamente, con la intención de que ésta lograra relajarse y pudiera dormir. La participante comentó que las prácticas de sanación cristiana y de las tradiciones orientales que aplicaba en su hermana enferma le producían gran bienestar a ésta: "Yo le trasmitía energía a mi hermana enferma, mientras una amiga le hacía la técnica de imposición de manos llamada Reiki. Yo hacía oraciones y plegarias de sanación para mi hermana y para otras mujeres internadas en el hospital oncológico. Mi hermana me decía que yo era su psicóloga ya que sentía que le levantaba el ánimo porque hacíamos afirmaciones de salud que habíamos aprendido en misas del grupo carismático. Me decía- 'cuando vos venís a verme, me siento bien porque destilás alegría. Lo que me hacés de sanación en los chakras me hace sentir mejor, siento menos dolor y más calma."

En relación a las prácticas de sanación o "healing" observadas, Benor (1991) se refiere a la sanación espiritual como una intervención sistemática de una o más personas que buscan ayudar a otro ser vivo a 
través de una intención focalizada, de un contacto a través de las manos o de pases de energía con el objetivo de mejorar la condición de quien lo recibe. Dossey (1993) afirma que tanto la plegaria como el trabajo de visualización mental -como forma de meditación- son recursos espirituales que producen efectos positivos en los enfermos por quienes otros sujetos rezan, a pesar de la distancia física entre el individuo que realiza la plegaria y el enfermo que la recibe. Dichos autores destacan las sensaciones de auto-confianza y de autovaloración positiva surgidas en quienes, siendo religiosos, usan las actividades de sanación para ayudar a sus familiares enfermos.

El adherir a creencias sobre la sanación como algo que colabora, no en la curación física de enfermedades graves, sino como un tipo de sanación energética, emocional, mental y espiritual, permitió que la participante sintiera satisfacción por hacer actividades que ayudaron a su familiar a morir en paz. El Padre Pérez del Viso (2006) señala al respecto: "Existen diversas plegarias como el Padrenuestro, el Avemaria e incluso partes del Evangelio que son utilizadas como oraciones para pedir por la sanación o curación de los enfermos y de quienes están por morir. Las plegarias peticionales son las más usadas para pedir por la recuperación de los enfermos, aunque en muchas ocasiones sus familiares y amigos sepan que es probable que no se recuperen."(Pérez del Viso,2006. Comunicación personal a la autora, 24 de abril).

María aprendió a cocinar comida macrobiótica y utilizó este tipo de alimentación natural como recurso para ayudar a su hermana enferma. Asi, integró conocimientos de la ciencia médica junto a recursos de sanación del credo católico y de otras tradiciones espirituales orientales, refiriendo que cuando ya no era posible la curación de las enfermedades de su hermana, había continuado realizando prácticas de sanación para ayudarla a sanar su alma de modo que pudiera morir en paz. Benor (2006) aclara que las prácticas de sanación energética- espiritual responden a creencias religiosas y espirituales sobre una concepción de sanación o healing no entendida como la curación de las enfermedades y los síntomas, sino como el alivio del malestar, del dolor y de los sentimientos y pensamientos negativos que pueden estar presentes en las personas enfermas y moribundas, y en quienes padecen sintomatología física, malestar, angustia o problemas psicológicos, entre otros. Beit Hallahmi y Argyle (1997), destacan que cuando ya no hay más posibilidad de sanación fisica, se apela a la sanación espiritual del alma que permite a la persona estar más en paz y morir mejor.

En su duelo, Maria continuó haciendo prácticas de sanación para si misma que le permitieron disminuir el cansancio y el estrés causados por las situaciones negativas de su duelo anticipado y del duelo posterior a la muerte. Las prácticas de sanación oriental fueron realizadas en forma conjunta a la meditación y a la gimnasia oriental denominada Tai Chi. Estas actividades fueron referidas como recursos espirituales que le permitieron disminuir el estrés, la angustia y el malestar, y alcanzar sensaciones de calma, relajación, sensaciones de bienestar mental y emocional y paz espiritual en el duelo.

Luego de la muerte de su hermana, la participante hizo plegarias de ayuda al difunto en las que rezaba por el descanso en paz del alma del ser querido fallecido: "Yo rezaba el Rosario como si estuviera meditando y pedía para que las almas de mi madre y de mi hermana descansaran en paz." Pargament, Koenig et al., (1998), señalan que las prácticas religiosas de plegarias influencian positivamente la salud mental en forma psicodinámica al producir efectos positivos a través de emociones que promueven actitudes de esperanza, perdón, aumento o afianzamiento de la autoestima, paz, bienestar, amor y compasión.

Otra de las actividades religiosas destacadas por la participante fue la lectura de textos. Los Evangelios fueron los principales textos que leía en su duelo anticipado en los momentos de malestar y angustia en que sentía la proximidad de la muerte: "La lectura me ayudaba a levantar el ánimo; me servía para encontrar respuestas a las situaciones difíciles que tenia que atravesar por la enfermedad de mi hermana y su falta de deseo de seguir viviendo después de la muerte de mi mamá. También leía para las personas del hospital que se sentían mal para levantarles el ánimo. Leer me ayudaba a mí para elevar mi conciencia y encontrar paz interior". Como efectos positivos de esta práctica fueron referidos: sentimientos de paz, disminución de pensamientos negativos, desarrollo de la conciencia, 
posibilidad de hallar respuestas a situaciones difíciles de toma de decisiones y un aprendizaje que ayudó a la participante a vivir con mayor y mejor calidad de vida.

La actividad religiosa como la lectura de textos fue utilizada por la participante en el marco de un estilo de afrontamiento activo y focal racional, en el que se enfatiza la búsqueda de soluciones a los problemas, y que fue eficaz al permitir encontrar nuevos significados a la vida, a la muerte y para la atribución de sentidos a la pérdida. Asimismo, Pargament (1997) refiere que esta actividad puede ser utilizada como estrategia de afrontamiento evitativo cuando la finalidad de los sujetos es poder distraerse y apartar su mente de los conflictos, lo cual les permite dejar de pensar de manera repetitiva y reflexionar posteriormente con más calma y claridad, así como para reducir el malestar vivenciado tanto por la muerte del ser querido como por los conflictos presentes en el duelo. Suls y Mullen (1982) plantean que los métodos de afrontamiento pueden cambiar a lo largo del tiempo, y que algunos pueden ser efectivos a corto plazo, mientras que pueden tornarse negativos a largo plazo.

Al mismo tiempo, la participante mencionó que la meditación como método de instrospección cristiana y modo de autoanálisis posibilitaba: "buscar adentro mío, cuando hacia introspección trataba de ver lo que tenía que resolver adentro mío.” Luego de sus estudios de budismo y de meditación oriental, Maria comenzó a meditar de otro modo. Sobre ello comentó: "como yo era muy especulativa, me puse a estudiar y a hacer prácticas de meditación oriental. Pasé de la reflexión a la práctica de la meditación y empecé a estar más en contacto conmigo misma, con mi interior, no sólo con mi mente racional." Durante el duelo anticipado y a posteriori de la muerte de su hermana, la participante realizó prácticas de meditación en forma cotidiana. Como efectos positivos alcanzados a través de esta práctica fueron mencionados los estados de: paz, bienestar espiritual, claridad para resolver problemas, fe en Dios y en si misma, tranquilidad, relajación, menor dolor y tristeza. Se pudo constatar que en este caso, la meditación fue un recurso útil para hallar soluciones a los problemas a partir del diálogo interno y de un trabajo realizado en conjunto, según el estilo de colaboración con Dios (Pargament,1997). Para Kabat
-Zinn (1997), dado que la mayor parte del estrés es mental, y una muerte en la familia supone gran nivel de estrés y malestar, el uso de la meditación resulta ser un recurso efectivo para el reestablecimiento de la armonía y del equilibrio interior del sujeto en duelo. Al producir estados positivos, la meditación sirve como un modo de protección frente al estrés cotidiano, y también es útil para el tratamiento de problemas de estrés crónico.

La participante mencionó en sus entrevistas que cuando hacia prácticas de meditación y plegarias, confiaba que sus oraciones serían escuchadas y que obtendría respuesta de Dios y/o de los demás seres superiores. Asimismo, comentó que el afrontamiento religioso espiritual a través de las prácticas religiosas espirituales fue eficaz para ayudarla a disminuir el estrés, el malestar, la angustia y el dolor ante la muerte y pérdida de su hermana, y para alcanzar estados positivos de calma, paz, claridad mental, bienestar emocional, físico, mental y espiritual. Mencionó como efectos positivos del uso de las creencias y las prácticas religiosas espirituales en el duelo los siguientes:

- $\quad$ aumento de la fe religiosa: "mi fe en Dios fue mi gran apoyo y sostén de mi misma";

- confianza en Dios: "en que Dios iba poniendo en mi camino lo que necesitaba durante la enfermedad de mi hermana";

- confianza en el apoyo de la amiga catequista y el sacerdote amigo,

- esperanza "que me permitía traspasar los estados de angustia y de dolor"

- mayor concentración en el presente: "las prácticas religiosas me ayudaban a estar más conectada conmigo misma y con lo que iba necesitando para enfrentar la enfermedad de mi hermana, sus tratamientos y la muerte de ella";

- disminución de sentimientos y pensamientos negativos: "la meditación y la oración me ayudaban a disminuir la angustia y los miedos que sentía ante la muerte de mi hermana";

- aumento de sentimientos positivos a partir de la meditación: "al concentrarme en pensamientos positivos en la meditación no dejaba que la angustia creciera en mi." 
En este caso, la lectura de textos sagrados, la oración, la sanación y la meditación fueron mencionadas como actividades de afrontamiento religioso espiritual realizadas durante el duelo anticipado y a posteriori de la pérdida. En éstas primó la modalidad de afrontamiento religioso activo, el estilo de colaboración con la deidad (Dios, el Espíritu Santo, Jesucristo, la Virgen Maria y diversos santos) en la realización de plegarias peticionales, oraciones y prácticas de sanación y meditación. El afrontamiento religioso espiritual y el estilo de colaboración con Dios o con la divinidad surge como uno de los predictores más fuertes de efectos positivos en la salud (Pargament, 1997).

Asimismo, se corroboró el predominio del afrontamiento religioso espiritual positivo que incluye el estilo colaborador, el reencuadre o la resignificación religiosa benevolente, y la consideración de Dios o de la deidad como benevolente. Koenig (1999), indica que el afrontamiento religioso positivo integra aspectos como la apreciación de Dios como benevolente, la tentativa de colaborar con Dios, la búsqueda de una relación de mayor contacto con Dios, la búsqueda de apoyo religioso espiritual de parte de la congregación religiosa o un representante de ella, la confianza en Dios, el ofrecer ayuda espiritual a otras personas, la purificación religiosa por medio de plegarias, oraciones, de pedir y otorgar perdón a otros. No se detectó ninguna estrategia negativa como el descontento con la congregación, con el representante del credo o la resignificación religiosa negativa del suceso. En este marco, es importante retomar a Pargament y Brant (1988), quienes sugieren que la religión puede actuar como una fuerza positiva, negativa o simplemente irrelevante cuando se considera la adaptación a sucesos de vida negativos, estresantes o traumáticos.

\section{RITUALES, APOYO SOCIAL Y RELIGIOSO ESPIRITUAL EN EL DUELO}

Maria comentó en sus entrevistas que la ceremonia de misa de cuerpo presente fue muy significativa ya que contó con la presencia de monjas de la escuela a la que había asistido, de un sacerdote amigo de la familia y de una amiga catequista. Destacó así el apoyo religioso y la contención emocional recibidos que le permitieron sentir: "sensación de paz y mucho alivio al poder encomendar al alma de mi hermana para que pudiera tener mayor desarrollo espiritual después de su muerte."

Conjuntamente, la participante señaló que dado que en el duelo anticipado careció de contención de parte de su marido, se apoyó en sí misma y en su fe en Dios, al no contar más con miembros de su familia de origen. Refirió: "Yo confiaba en Dios y en el poder sanador del Espíritu Santo a quienes les rezaba y pedía por mi hermana, enferma. Al mismo tiempo, sentía el apoyo en mí misma, en mi fe en Dios y en los santos a los que les rezaba". Destacó el gran apoyo religioso recibido de una amiga catequista del grupo carismático de la Iglesia en el que participaba desde su juventud. Sobre ello, expresó: "Sentí mucho apoyo y acompañamiento religioso, espiritual y emocional de una amiga del grupo carismático al que asistia. Fue como que Dios puso a esta persona en mi camino porque ella fue como mi guía y me apoyo muchísimo. Me acompañaba todo el tiempo cuando mi hermana estuvo internada y después de su fallecimiento. Yo sentía que me ayudaba mucho porque me comprendía. También estuvo junto a mí en la misa de cuerpo presente y en el entierro de mi hermana".

La participante señaló la importancia del apoyo religioso recibido de parte de un sacerdote amigo de su familia quien estuvo presente en el duelo anticipado, a través de visitas a su hermana enferma antes y después de sus cirugías. María refirió que pudo comulgar y rezar junto a su hermana, hacer plegarias y oraciones junto al clérigo, en las que pedía por la sanación de ésta A posteriori de la muerte del ser querido, el apoyo y acompañamiento emocional y religioso de dicho sacerdote y de una amiga catequista tanto en la misa de cuerpo presente como el entierro de su hermana fueron factores que ayudaron a aliviar la angustia y el vacio ante la pérdida. Levin (1994), plantea que frente al sentimiento de tristeza por la pérdida de un ser querido, los rituales funerarios suelen crear una sensación de unión, de consenso y de acuerdo entre quienes participan, según las distintas creencias sociales y religiosas a las que adhieren los sujetos. Los rituales mortuorios religiosos utilizan rezos que refuerzan las creencias religiosas, promoviendo estados de tranquilidad, confianza y sentido de la vida en los deudos. Campos, Páez et al., (2004) señalan que 
el apoyo social, a través de la presencia de los otros, refuerza la autoestima y amortigua el estrés que sufre quien ha perdido a un ser querido.

Asimismo, fue relevante el apoyo recibido en el duelo anticipado de parte de pastores evangélicos que frecuentaban el hospital oncológico y visitaban a su hermana y a otras mujeres enfermas de cáncer. Maria podia conversar con dichos clérigos sobre temas espirituales, rezar y leer los Evangelios. Destacó lo siguiente: "Los pastores evangelistas me apoyaron mucho durante la internación de mi hermana [..]Yo siento que la religión protestante es buena ya que uno habla directamente con Dios. Uno toma conciencia de sus pecados, errores y limitaciones de su fe. A mi y a mi hermana nos ayudaron muchísimo durante su enfermedad."

La participante mencionó su participación activa y el apoyo religioso espiritual, emocional y cognitivo que pudo brindar a mujeres enfermas internadas en el hospital oncológico junto a su hermana. Señaló las conversaciones, los rezos, las lecturas de textos sagrados, las oraciones y las prácticas de sanación católica y de tradiciones orientales como recursos con los cuales pudo acompañar a otras personas que sufrían junto a su hermana. Refirió la realización de dichas actividades desde su adhesión a valores cristianos de servicio, caridad y compasión. Asimismo, participó en velorios de mujeres fallecidas en el hospital oncológico, y mencionó el consuelo que brindó a los familiares con los que había compartido el período de hospitalización de su hermana: "Les daba Reiki a otras mujeres enfermas del hospital oncológico donde estaba internada mi hermana. Conversaba y rezaba con ellas, leía textos sagrados, hacíamos plegarias con sus familiares. Iba a los velorios de las mujeres que habían fallecido en el hospital oncológico. Así, podía dar consuelo a quienes me habían acompañado durante la internación de mi hermana. Todo eso me hacía sentir bien".

Se debe distinguir entre el apoyo religioso y espiritual horizontal que se da entre los pares del grupo espiritual, del apoyo religioso espiritual vertical, del clérigo hacia las personas religiosas. El apoyo social, emocional, cognitivo y religioso brindado por los clérigos hacia los deudos es un tipo de apoyo formal de parte de la institución religiosa. El apoyo emocional puede ser brindado a través del compañerismo y la amistad entre los pares de un grupo religioso que se encuentran para hacer juntos plegarias, oraciones, meditaciones y rituales, así como a través de llamados telefónicos, visitas a los deudos, entre otros (Fernández, Ubillos, Zubieta y Páez, 2001).

Maton y Wells (1989), señalan que los rituales funerarios, las ceremonias, las plegarias, las prácticas de sanación y de meditación, el acompañamiento y el consuelo a los deudos, los consejos sobre cómo afrontar el duelo son recursos religiosos que brindan apoyo social, emocional, práctico y espiritual a quienes han sufrido la muerte de un familiar. La disponibilidad de apoyo social promueve la capacidad de sobreponerse a frustraciones y a duros desafíos, implica un marco de vínculos continuos o intermitentes que desempeñan un papel importante en el mantenimiento de la integridad física y psíquica del individuo a lo largo del tiempo. El apoyo social pone en juego dos elementos importantes: la percepción de que hay un número suficiente de otros disponibles a quienes uno puede acudir en momentos de necesidad, y un grado o nivel de satisfacción con el apoyo disponible (Saranson et al., 1985). Estos factores varían de una a otra persona, ya que algunas pueden pensar que un gran número de ayuda disponible puede posibilitar el apoyo social; mientras que para otras, una sola persona es suficiente. Asimismo, la satisfacción con el apoyo percibido y con el apoyo disponible está influenciada por factores como la autoestima y la sensación de control. Tanto las experiencias previas como la propia personalidad influencian a cada persona para que perciba o considere el apoyo disponible como satisfactorio o insatisfactorio (Fernández, Ubillos, Zubieta y Páez, 2001).

En este caso aparecieron referencias a sentimientos de soledad y sensaciones de orfandad cuando la muerte del ser querido se sumó a la pérdida previa del otro progenitor. La participante debió levantar la casa de su madre y hermana y proceder a su venta, lo que sumó mayor dolor y estrés al duelo posterior. Jaramillo (1999) y Levy (1999) refieren el sentimiento de "orfandad" que siente el adulto en el momento en que se queda solo sin sus padres: "La orfandad es la sensación definitiva de que ya para nadie seremos hijos, por lo que nos percibimos definitivamente como 
adultos" (Jaramillo, 1999; p. 201). Ante ello, el saber que podía contar con el apoyo de su esposo y de su hija fue importante para ayudar a disminuir el sentimiento de soledad surgido a partir de la pérdida de los miembros de su familia de origen. María mencionó en sus entrevistas: "Fue muy importante que mi marido me dijera: 'ahora nos tenés a tu hija y a mí que somos tu familia". Tomar conciencia de las ganas de vivir y del aumento de su vitalidad le permitió darse cuenta que había podido aceptar las pérdidas de su hermana y su madre. La participante señaló al respecto: "Todo fue muy seguido, me venía el tema de 'las perdí' y pensaba enseguida: 'están mejor del otro lado en otro plano más elevado' . Ahora estoy entendiendo lo que es elaborar el duelo, ya que para mi hermana era terrible perder a mi mamá y no tenía ganas de seguir viviendo sin ella. Yo me di cuenta que, después del sepelio de mamá, yo tenía ganas de seguir viviendo. Yo las quería a las dos, las amaba; pero ahora me doy cuenta que ya no las necesito para seguir viviendo".

\section{AFRONTAMIENTO NO RELIGIOSO DE LA PÉRDIDA}

En las entrevistas, Maria mencionó distintas actividades físicas o deportivas, cognitivas, socioculturales y expresivas que realizó en el duelo anticipado y posterior a la pérdida. Como modalidad de afrontamiento físico realizó un tipo de meditación en movimiento de origen chino denominado Tai Chi que la ayudó a disminuir el estrés y a reestablecerse energéticamente a posteriori de la muerte de su hermana.

Como modalidad de afrontamiento cognitivo, la participante comentó que durante el primer año de duelo leyó textos religiosos de su credo y de otras tradiciones espirituales en su hogar. Al finalizar dicho período, pudo retomar su tarea profesional como docente de nivel secundario y universitario y comenzó a estudiar Psicología Sistémica. Estos estudios le permitieron tomar conciencia y comprender lo sucedido a su hermana en relación al rol que ocupaba en la familia y a la relación de simbiosis con su madre, como también al desarrollo de enfermedades físicas y psicológicas sufridas a posteriori de la muerte de su progenitora. María destacó el afrontamiento cognitivo a través de estudios de Psicología Sistémica como los que le permitieron desarrollar una comprensión mayor de los procesos de desarrollo de las enfermedades y de las causas de la depresión del ser querido. Según la participante: "leer libros de psicología sistémica me sirvió para encontrar respuestas a las situaciones difíciles que tuve que atravesar de la enfermedad de mi hermana, y a la decisión de ella de no querer seguir viviendo después de la muerte de mamá; esta actividad también me ayudaba para levantar el ánimo."

El afrontamiento focal -racional utilizado a partir de la lectura de textos colaboró para poder hallar conocimientos del área de la psicología que le permitieron atribuir sentido a temas complejos para los cuales las creencias religiosas no le resultaban suficientes. Este estilo incluye centrarse en el problema para poder actuar y permite pensar que se aprendió algo a partir de la situación negativa estresante (Fernández, Páez, Ubillos \& Zubieta; 1996).

Como modalidad de afrontamiento socio-cultural, María señaló que había dejado de hacer actividades como las de ir al cine, a conferencias y al teatro con sus amigas durante su duelo anticipado. Fueron sus amistades quienes la acompañaron a cuidar a su madre y a su hermana enfermas. A posteriori de la pérdida, la participante permaneció más tiempo en su hogar en compañía de su esposo y de su hija porque sentía que los había descuidado al tener que cuidar a su madre y hermana enfermas. Hacia el final del primer año de duelo, se sentía con más ganas y energía para salir con sus amigas, y también retomó sus actividades docentes y sus estudios. El estar más en contacto con su familia y sus amistades le hizo sentir más alegría y vitalidad, mayor conexión con la vida y con sus seres queridos. En el segundo año de duelo, María retomó sus actividades socioculturales con amistades y comenzó a mirar televisión aquellos programas relacionados con temas de salud, religión, espiritualidad y procesos de sanación.

\section{EFICACIA DEL AFRONTAMIENTO DEL DUELO}

En sus entrevistas, Maria señaló la importancia de la religión y la espiritualidad y de sus estudios de Psicologia Sistémica como recursos eficaces para el afrontamiento de las pérdidas por muerte de sus seres 
queridos. En este caso, se constató que los recursos de afrontamiento religioso espiritual prevalecieron sobre los de afrontamiento no religioso, tanto en el duelo anticipado como en el duelo posterior a la pérdida. Al mismo tiempo, el tipo de afrontamiento religioso espiritual fue complementario a las modalidades del afrontamiento no religioso cognitivo, físico $\mathrm{y}$ socio cultural. Se corroboró la eficacia de ambos tipos de afrontamiento como modos de enfrentar las enfermedades, el duelo anticipado, la muerte y pérdida del ser querido. Conjuntamente, se detectó en la participante una actitud de flexibilidad, más que de rigidez, que permitió una variación de estilos y modalidades del afrontamiento religioso espiritual que redundó, probablemente, en su eficacia.

Parkes (1996), afirma que los esfuerzos de afrontamiento pueden ser paralelos y no necesariamente excluyentes los unos de los otros. Por su parte, Paloutzian (2005) y Pargament (1997) consideran que las personas religiosas que logran perseverar y mantener sus creencias y prácticas religiosas en momentos de gran estrés podrán mantener y sentir más fortalecida su fe religiosa. Parkes (1998) sostiene que el proceso de afrontamiento puede llevar tiempo y variar durante diversos períodos del duelo. Es necesario poner atención a las posibilidades y esfuerzos que llevan a cabo los sujetos que afrontan distintos tipos de duelos, por lo que se deberá tener en cuenta aspectos como: la cantidad de esfuerzos realizados por los sujetos en duelo, el tiempo empleado, el esfuerzo al aplicar determinadas estrategias y el éxito de los esfuerzos realizados. Un estilo o modo de afrontamiento puede tener distintos efectos e implicancias en diferentes momentos. Lo más importante es observar si a través de la estrategia de afrontamiento la persona está yendo en una dirección positiva que le permita alcanzar efectos positivos, y si está usando recursos que la ayuden afrontar la situación de estrés. En ocasiones, cuando el proceso de afrontamiento es positivo, las personas no llegan a darse cuenta de que sus familiares, las instituciones o las amistades les han brindado apoyo y contención afectiva. Otras veces, éstos perciben que sus modos de afrontamiento entran en coalición con lo que el sistema social tiene a su disposición para su uso.

\section{COMENTARIOS FINALES}

La participante religiosa católica destacó haber logrado un mayor desarrollo de su religiosidad y espiritualidad a partir de enfrentar la muerte de su familiar y de alcanzar una visión de la muerte como finitud de la vida. El atravesar un proceso de duelo anticipado le permitió reafirmar su fe religiosa, desarrollar mayor confianza en sí misma, en sus creencias y prácticas religiosas espirituales y en los clérigos que acompañaron su proceso de duelo. Lo vivenciado redundó en una comprensión más profunda del sentido espiritual de la vida, en la profundización de valores éticos de amor, compasión, altruismo, tolerancia y respeto interreligioso del sujeto mencionado (Yoffe, 2012a).

El atravesar un duelo anticipado permite al sujeto religioso brindar acompañamiento emocional, práctico, cognitivo y espiritual al familiar enfermo y ayudarlo a morir en paz. El afrontamiento religioso espiritual (a través de creencias, prácticas religiosas y espirituales y rituales) y el apoyo social y religioso espiritual colaboran en el alivio del dolor y malestar del familiar enfermo y del deudo. Asimismo, posibilitan que los cuidadores desarrollen estados positivos de paz, bienestar personal y espiritual y disminuyan su aflicción ante la muerte y pérdida del ser querido. Todos estos factores colaboran en el afrontamiento y en la aceptación de la pérdida.

Stroebe y Stroebe (2003) destacan los efectos positivos de los cuidados espirituales en familiares enfermos y en los cuidadores mismos en los procesos de duelo anticipado. Aunque los cuidadores no puedan controlar la enfermedad del ser querido, tienen la posibilidad hacerse cargo de la situación, controlando las tareas de acompañamiento de su familiar moribundo. Percibir que se tiene cierto sentido de control es muy diferente a cuando uno se siente desvalido al enfrentar situaciones en las que no es posible controlar nada de lo relacionado con la enfermedad de un ser querido moribundo. La nueva filosofía de vida que puede surgir a partir de un duelo puede asociarse a un fortalecimiento de las creencias religiosas, a una búsqueda y a un crecimiento espiritual que pueden resultar beneficiosos para los deudos (Pargament et al., 1990). 


\section{REFERENCIAS}

Attig, T. (2003). Respecting the Spirituality of the Dying and the Bereaved. En Corless,I., Germino, B.B.,\& Pittman.MA.(eds). Dying, Death and Berevament. New York: Springer Publishing Company, 61-78.

Basabe, N., Paéz, D., Usieto, R., Paicheler, H., y Deschamps, J.C. (1996). El desafío social del SIDA. Madrid: Fundamentos.

Benor,D.(1995). Spiritual Healing: a unifying influence complementary therapies. Complementary Therapies in Medicine, 3(4), 234-238. Recuperado el 11 de noviembre de 2007 de htpp//www. WholisticResearch.com.

Benor, D.(2006). Spiritual Healing and Psychotherapy. New Jersey. Wholistic Healing Publications.

Betancour, D.(2005). Fuentes de sanación. En los Sacramentos, Cristo continúa tocándonos para sanarnos. (Catic 1504). Buenos Aires: Tierra Nueva.

Beit-Hallami,B., \& Argyle, M. (1997). The Psychology of Religious Belief and Experience. London - New York: Routledge Editions.

Boisen,A.T.(1955). Religion in crisis and customs: a sociological and psychological study. Westport, CT: Greenwood Press.

Campos, M., Páez,D., \& Velasco, C. (2004). Afrontamiento y regulación emocional de hechos traumáticos: un estudio longitudinal sobre el 11M. En Ansiedad y Estrés, 10 (2-3), 277-286.

Campos, M., Páez, D., Fernández-Berrocal, P., Igartúa, J.J., Méndez, D., Moscoso, S., Palomero, C., Pérez, J.A., Rodríguez, M., Salgado-Velo, \& Tasado, J. (2004). Las actividades religiosas como formas de afrontamiento de hechos estresantes y traumáticos con referencia a las manifestaciones del 11 -M. Ansiedad y Estrés, 10 (2-3), 1-11.

Dossey, L. (1993). Healing words. The power of prayer and the practice of medicine. San Francisco: Harper Editions.

Endler, N.S. y Parker, J.D. (1990). Stress and anxiety: Conceptual and assessment issues: Special issues II-1. Stress Medicine, 3, 243-248.

Fernández, I., Ubillos, S., Zubieta, E., \& Páez, D. (2001). Cuadernos de Práctica de Psicología
Social de la Salud. Facultad de Psicología, Universidad del País Vasco.

Folkman, S. \& Moskowitz,J.T. (2000). Positive Affect and the Other Side of Coping. En American Psychologist, 55, (6), 647-654.

Folkman, S., Moskowitz, J. T., Ozer, E. M., \& Park, C. L. (1997). Positive meaningful events and coping in the context of HIV/ AIDS . En B. H. Gottlieb (Ed.), Coping with chronic stress. New York: Plenum, 293-314.

Folkman,S. (2007). Revised Coping Theory and the Process of Bereavement. En Stroebe, M.S., Stroebe, W., Hansson, R.O. \& Schut, H. (Eds). (2007). Handbook of Bereavement Research Consecuences, Coping and Care. Washington: American Psychological Association, 563-583.

Frankl, V.E. (1994). El hombre doliente. Fundamentos antropológicos de la psicoterapia. Barcelona: Herder.

Frankl, V. E. (2004). El hombre en busca de sentido. Barcelona: Herder.

Freud, S. (1927/1961). The future of an illusion. New York: Norton.

Goleman, D. (1997). La salud emocional. Conversaciones con el Dalai Lama sobre la salud, las emociones y la mente. Barcelona: Kairós.

Hufford, D.J. (2005). An analysis of the field of spirituality, religion and health.(S/RH) Area 1 Field Analysis. En www. metanexus.net/tarp., 12/10/2006.

Kabat-Zinn, J. \& Salzberg, S. (1997). La atención vigilante como medicina. En Goleman, D. (1997) (ed.). La salud emocional. Conversaciones con el Dalai Lama sobre la salud, las emociones y la mente. Barcelona: Kairós; 123- 164.

Koenig, H., Mc Cullough, M., \& Larson, D. (2001). Handbook of Religion and Mental Health. New York: Oxford University Press.

Koenig, H. (1999). The healing power of faith. Science explores medicine's last great frontier. New York: Shimon \& Schuster Editions.

Kushner,H.(1987). Por qué las cosas malas le suceden a la gente buena. México: Diana.

Jaramillo, I. F. (2001). De cara a la muerte. Cómo afrontar las penas, el dolor y la muerte para vivir plenamente. Santiago de Chile: Andrés Bello. 
Lazarus, R. S., \& Folkman, S. (1984). Stress, Appraisal, and Coping. New York: Springer Publishing Company.

Lazarus, R. S. \& Folkman, S. (1987).Transactional theory and research on emotions and coping. European Journal of Personality. Volume 1, Issue 3, September 1987 , 141-169.

Levin, J. S. (1994). Religion and health: Is there and association, it is valid and it is causal? Social Science and Medicine,11, 1475-1482.

Levy, A. (1999). The orphaned adult. Understanding and coping with grief and change after the death of our parents. Massachusetts: Perseus Books.

Maton,K.,\& Wells,E. (1995). Religion as a Community Resource for Well Being: Prevention, Healing and Empowerment Pathways. Journal of Social Issues, 51(2).

Oman, D. \& Thoresen, C. E. (2005). Do Religion and Spirituality influence Health? En Paloutzian \& Park (eds). Handbook of the Psychology of Religion and Spirituality. New York: The Guilford Press,pp.435-459.

Paloutzian, R.F., \& Park, C. L. (eds).(2005). Handbook of the Psychology of Religion and Spirituality. New York: The Guilford Press.

Overberg,K.,SJ.(2002). The Mystery of Suffering: How Should I Respond? . New York: St. Anthony Messenger Press. En: www.American Catholic. com, 25/10/2006.

Páez, D., Basabe, N., Ubillos, S., \& González-Castro, J.L. (2007). Social sharing, participation in demonstrations, emotional climate, and coping with collective violence after the march 11th Madrid bombings. Journal of Social Issues, 63(2), 323-337.

Páez, D., Bilbao, M., \& Javaloy, F. (2008). Del trauma a la felicidad. Los hechos negativos pueden generar creencias positivas y crecimiento. En Casullo, M. M. (comp). Prácticas de Psicología Positiva. Buenos Aires: Lugar Editorial, 159-202.

Pargament, K. I., \& Brant, G. R. (1998). Religion and coping. En H. G. Koenig (Ed.), Handbook of religion and mental health (pp. 111-128). San Diego, CA: Academic Press.

Pargament, K. I.; Smith, B.; Koenig, H. G. (1996). Religiuos coping with the Oaklahoma City bombing: The brief RCOPE. Paper presented at the meeting of the American Psychological Association, Toronto.

Pargament, K. I., Ensing, D.S, Falgout, K., Olsen, H., Reilly, B., Van Haitsma, K \& Warren,W. (1990) Religious Coping Activities Scale: God Help Me: (I): Religious coping efforts as predictors of the outcomes to significant negative life events. Reviewed by P. J. Watson. God Help Me: (I): En Hill, P. \& Hood Jr, P. (eds.) (1990). Measures of Religiosity. Birmighman-Alabama: Religious Education Press, 343-347.

Pargament, K. I., \& Park, C. L., (1995) Merely a Defense? The Variety of Religious Means and Ends. Journal of Social Issues, 51, (2,) pp 13-32, Summer 1995.

Pargament, K. I; Smith, B.W; Koenig, H. G. \& Perez,L. (1998). Patterns of Positive and Negative Religious Coping with Major Life Stressors. Journal for the Scientific Study of Religion, 37 (4) (Dec., 1998), pp. $710-724$

Pargament, K. I. (1997). Psychology of Religion and Coping. Theory, research and practice. New York-London: The Guilford Press.

Pargament, K. I., \& Brant, C. (1998). Religion and coping. En Koenig, H. (ed). Handbook of Religion and Mental Health. San Diego: Academic Press, 112-129.

Parkes, C. M. (1998). Bereavement. Studies of grief in adult life. Madison, CT: International Universities Press.

Parkes, C. M. (2001). Bereavement. Studies of grief in adult life. Philadelpia: International Universities Press.

Parkes, C. M., \& Markus, A. (eds).(1998). Coping with Loss: Helping patients and their families. London: BMJ Publishing Group.

Pérez del Viso, I. SJ. (2006). Comunicación personal con la autora sobre "Creencias, prácticas y rituales en el credo católico romano", 24 de abril.

Sarason, I. G., \& Sarason, B. R. (1985).Social supportInsights from assessment and experimentation. En Sarason \& B. R. Sarason (eds.), Social support: Theory, research and applications. Boston: Martinus Nijhoff, 39-50. 
Spilka, B. (2005). Religious Practice, Ritual and Prayer. En Handbook of the Psychology of Religion and Spirituality. New York-London: The Guilford Press, 43-61.

Spilka, B., Hood, R.W. Jr, Hunsberger, B., \& Gorsuch, R.(2003).The psychologyof religion: An empirical approach (3ed). New York: Guilford Press.

Stroebe, W., \& Schut, H. (eds.) (2007). Handbook of Bereavement Research: Consequences, Coping and Care. Washington, DC: American Psychological Association, 563-584.

Stroebe, W., \& Stroebe, M.S. (1987). Bereavement and health. New York: Cambridge University Press.

Stroebe, M., Hansson, R., Stroebe, W., \& Schut, H. (eds.). (2007). Handbook of Bereavement Research: Consequences, Coping and Care. Washington, DC: American Psychological Association.

Stroebe, M., Stroebe, W., \& Hansson, R. (1999). Handbook of Bereavement: Theory, Research and Intervention. London - New York: Cambridge University Press.

Stroebe, M. S., \& Schut, H. (2007). Models of Coping with Bereavement. En Stroebe, M., Hansson, R., Stroebe, W., \& Schut, H. (Eds.). Handbook of Bereavement Research: Consequences, Coping and Care. Washington, DC: American Psychological Association, 375-404.

Stroebe, M., Hansson, R., Stroebe, W., \& Schut, H. (Eds.) (2007). Handbook of Bereavement Research: Consequences, Coping and Care. Washington, DC: American Psychological Association.

Suls, J., \& Mullen, B. (1982). From the cradle to the grave: Comparison and selfevaluation across the life-span. In J. Suls (Ed.), Psychological perspectives on the seff, 1, pp. 97-125). Hillsdale, NJ: Lawrence Erlbaum.

Wortman, C. B., Silver, R. C., \& Kessler, R. C. (1993). The meaning of loss and adjustment to bereavement. En M. S. Stroebe, W. Stroebe, \&
R.O. Hansson (Eds.), Bereavement :A sourcebook of research and interventions (pp. 349-366). London: Cambridge University Press.

Yoffe, L. (2006). Efectos positivos de la religión y la espiritualidad en el afrontamiento de duelos. Psicodebate 7, Psicología, Cultura y Sociedad. Psicología Positiva. Buenos Aires: Universidad de Palermo, 193-205.

Yoffe, L. (2008). Religión, espiritualidad y sentido de la vida en los duelos. En Casullo, M. M.(comp). Prácticas en Psicología Positiva. Buenos Aires: Lugar Editorial, 269-298.

Yoffe, L. (2012a). La influencia de las creencias y prácticas religiosas espirituales en el afrontamiento de la pérdida por muerte de un ser querido. Disertación doctoral no publicada. Universidad de Palermo. Buenos Aires, Argentina.

Yoffe, L. (2012b). Beneficios de las prácticas religiosas espirituales en el duelo. Avances en Psicología, 20 (1). Enero - Julio, 9-30. Disponible en: http://www. unife.edu.pe/pub/revpsicologia/avances2012.

Yoffe, L. (2012c). La religión y la espiritualidad en los duelos: desde la visión de la psicología positiva. En: Alarcón, R.A.(Dir.). Psicología Positiva. Lima: Facultad de Psicología y Humanidades, Universidad Femenina del Sagrado Corazón, 83116.

Yoffe, L. (2014a). Nuevas concepciones sobre los duelos por pérdida de seres queridos. En Avances en Psicología, 21 (2). Revista de la Facultad de Psicología y Humanidades, Lima: Universidad Femenina del Sagrado Corazón, 129-154.

Yoffe, L. (2014b). Rituales funerarios y de duelo colectivos y privados, religiosos o laicos. En Avances en Psicología, 22(2) Agosto-Diciembre, 145-163.

Yoffe, L. (2015).Rituales funerarios, apoyo y consuelo en los duelos. En Revista Remanso 18. Bogotá: Corporación Nacional e Internacional de Funerarias Remanso, 90- 107. 